\title{
Impact of Lightning Impulse on Electric Field Stress of Spacer in Single Phase Gas Insulated Busduct
}

\author{
M.Mohanlal Naik, G.V.Nagesh Kumar
}

\begin{abstract}
During the last two decades, for reliable power supply, GIS have found a broad range of application in power systems because of their high reliability, easy maintenance, small space requirement, etc. Gas insulated sub-stations employs a superior dielectric gas, SF6 at moderate pressure for phase to phase and phase to ground insulation. Several troubles and system outages in GIS have been reported world-wide due to insulation failures which resulted in the intensification of electric field along the spacer surface and especially at the triple point electrode - spacer-gas. Hence, it was required to reduce the rate of insulation failure. In this work, Conventional cone type spacer geometry is taken for which field study has been done. Electric field stresses developed by the cone type spacer on the surface of the spacer and also at the triple junction is determined. It is found that the electric field stress at the surface of the spacer is maintained uniform, the electric field stress at the critical junctions formed by the conductor, solid insulator and SF6 gas is not maintained at minimum value. Metal inserts are considered as a means to reduce the stress at the triple point junction. The impact of Lightning Impulse on the Electric Field Stress along the spacer is carried and the reduction of stress is mitigated with the insertion of Metal Inserts.
\end{abstract}

Index Terms - Electric Field Stress, Spacer, GIS, FGM, TPJ

\section{INTRODUCTION}

In this present generation, utility of power is more that feeds requirement of $\mathrm{HV}$ power equipment like $\mathrm{HV}$, Transmission HV substations. Substations are the major important thing to control the voltage with different power electronic equipments. The GIS take less space to build HV substations compared to open air substations because of using SF6 insulated gas with enclose the conductor in GIS may subject to HV charge field stress because of Lightning, switching and small defect on surface of conductor like protrusion, dip. This down of charge field stress at triple point junction (TPJ) cause support insulator damage.

They studied various defect in GIS like contaminated partial void and protrusion formed during manufacturing and transportation. These defects could cause high charge field density, which leads to insulation breakdown during steady state condition, in this paper they studied two types of defects like metallic partial and void with different sizes and different position in epoxy spacer by ANSYS software. The degree of charge field strength on particles is depends upon position and size of a particle [1]. These defect cause more harm during steady state and transient state operation

Revised Manuscript Received on July 10, 2019

M.Mohanlal Naik, Department of EEE, JNTUA College of Engineering, Pulivendula, A.P, India.

G.V.Nagesh Kumar, Department of EEE, JNTUA College of Engineering, Pulivendula, A.P, India. of power systems. To find, these characteristics of particle discharge by different methods like optical method, chemical method and electromagnetic method. Free particle is the major problem in GIS. They are some other types of defects like void and pits. The void defects are formed during the manufacturing of spacer and conductor micro voids which from inside the spacer. They do not show more impact on GIS during installation it will effect more on GIS for long time operation the charge field effect due to void is depend on size and shape of void [2].delamination is another kind of problem which can be observed between support insulator and enclose. This kind of problems will occur because of long time operation. This defect in GIs will increase charge field stress at enclose end, to decrease that field stress at enclose with FGM technique. Modulated cone spacer get influences to decrease charge at TPJ.three different permittivity levels of support insulator charge field will be calculated by computational methods[3] GIs is not only disturbed by manufacturing and internal factors but also with External factors like transmission faults, lightning. Transmission Faults shows, more impact on steady state condition for a long time and switching shows, less voltage disturbance for a short time but lightning shows high stress for a short duration on transmission line which is connected to the substations. Lightning are irregular shape of impulse, which can't have a standard waveform. This irregular shape of impulse show more charge field stress than standard shape impulse. During lightning, the wave travel from lightning point to substation point, with propagation mechanism like reflection and refraction. This lightning voltage impulse cause's insulation failure in GIS [4-5]. The Spacer is to be designed to protect against flash over and it should have high insulation strength must with stand with respect to applied voltage. The numerical and experimental of SF6 and epoxy space, insulation behavior different from AC to DC. They generalized in order to find, the reliable spacer in different application like constant DC voltage and varying AC voltage at GIS. They implemented some optimal design on canonical spacers and port type spacer in constant DC voltage and varying $\mathrm{AC}$ voltage application studied operating stress and dielectric property. The design of canonical spacer and post type spacer are optimal and economical [6]. The development of insulation property in gas insulated substation (GIS) by application of 


\section{IMPACT OF LIGHTNING IMPULSE ON ELECTRIC FIELD STRESS OF SPACER IN SINGLE PHASE GAS INSULATED BUSDUCT}

Functionality Graded Material (FGM) support insulator. The charge field distribution of permittivity near and around the support insulator can be controlled. From the charge field view point, reduction of field distribution was developed by the applicability of FGM spacer these numerical calculations are verified by computational results. By this method, maximum charge field stress can be minimized only by changing the volume of the spacer, so that the cost of the spacer may reduce upto a level. The minimum charge field stress can be reduced and the charge distribution get more uniform and it is very suitable for gas substation [7].The charge filed distribution in gas substation is non-uniform ,with FGM spacer distribution of charge field was minimized at (TPJ) for different voltage levels, so it is more reliable. The distribution of charge field strength it still below the breakdown voltage of insulation with epoxy spacer material. A small percentage of titanium oxide is added with FGM given more reduction of charge field strength [8]. The FGM technique applied on disk type spacer, from the charge field stress was decreased at TPJ when a contaminated charge particle present near and far from the conductor. The charge field stress was reduced by U-shaped FGM spacer then epoxy spacer. When the gas mixture were increased, the breakdown voltage strength of the gas also increased, leads high insulation. The gas mixture of SF6, N2, CO2 and air which reduces the cost of the material and increases, insulation property. The severity of SF6 gas on the environment also reduced; if any leakage were happened at the time of gas leak the breakdown voltage increases, when the radius of contaminated particle increases in same manner, the breakdown voltage increases when the length of contaminated particle decreases. The FGM spacer has better charge field characteristic than the epoxy spacer at TPJ [9].

In this paper, cone shaped type spacer is designed. Study on charge field stress in GIS enclose along cone shaped spacer surface. The FGM cone type spacer is used to maintain uniform charge field stress along the cone shape surface and also, charge field stress at (TPJ) is studied. The charge field stress at TPJ is more than along the surface, so mental inserter are used to decrease the charge field stress along support insulator and TPJ.

\section{COMPUTATION OF ELECTRIC FIELD}

In GIS two type of insulator are used SF6 gas and siliconepoxy SF6 gas is used as insulator along the encloser, and silicon-epoxy is used as insulator support in encloser. The charge field stress is linear increased along the surface which causes failure of insulator support. The charge field stress along surface and Triple Point Junction (TPJ) is studied. The FGM technique is used to maintain uniform charge field stress At steady state the electrostatic field within anisotropic dielectric material, assuming a Cartesian coordinate system, and Laplacian field, the electrical energy $\mathrm{W}$ stored within the whole volume $\mathrm{U}$ of the region considered is:

$$
\mathrm{W}=\frac{1}{2} \int_{\mathrm{u}} \varepsilon\left|\operatorname{gradV}^{2}\right| \mathrm{dU}
$$

As it is not possible to find a continuous function for the whole area $\mathrm{A}$, an adequate discretization must be made. So all the area under consideration is subdivided into triangular elements hence:

$$
\frac{\mathrm{W}}{\varphi}=\frac{1}{2} * \varepsilon * \sum_{\mathrm{i}=1}^{\mathrm{n}}\left[\left\{\frac{\partial \mathrm{V}_{\mathrm{x}}}{\partial \mathrm{x}}\right\}^{2}+\left\{\frac{\partial \mathrm{V}_{\mathrm{y}}}{\partial \mathrm{y}}\right\}^{2}\right] * \mathrm{~A}_{\mathrm{i}}
$$

Where $\mathrm{n}$ is the total number of elements and $\mathrm{A}_{\mathrm{i}}$ is the area of the $i^{\text {th }}$ triangle element. So the formulation regarding the minimization of the energy within the complete system may be written as

$$
\frac{\partial \mathrm{X}}{\partial\{\mathrm{V}(\mathrm{x}, \mathrm{y})\}}=0 \quad \mathrm{X}=\frac{\mathrm{W}}{\varphi}
$$

Within each element the electric field strength is considered to be constant and the electric field strength is calculated as

$$
\vec{E}=-\dot{i} \frac{\partial V(x, y)}{\partial x}-\vec{j} \frac{\partial V(x, y)}{\partial y}
$$

\section{FGM FOR CONE SPACER}

A plain cone type insulator has a constant permittivity. So the charge field stress near the conductor is more and charge field stress at encloser is less. This leads to failure of insulator support. At (TPJ) charge field density is more this cause discharge of a particle at triple junction. The FGM technique is used to maintain uniform charge field stress, in this method different types of permittivity levels are used for maintain uniform charge filed stress. Practically, this can be done by applying centrifugal force on spacer.

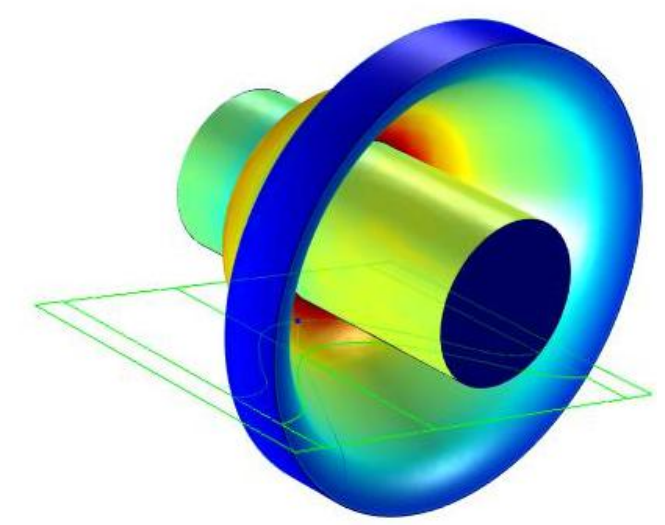

Fig 1. FGM Spacer for Single Phase GIS

\section{ELECTRIC FIELD DISTRIBUTION WITH METAL INSERTS}

Electric field stress is decreased by using MI in cone insulator, when compared with the plain cone and also charge field stress can be decreased at TPJ compared with plain type 


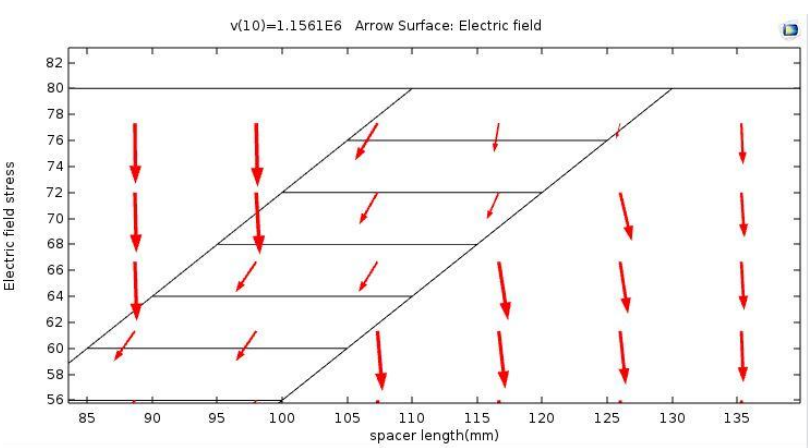

Fig 2: Quiver plot at Anode end / Type 1 / GL-FGM

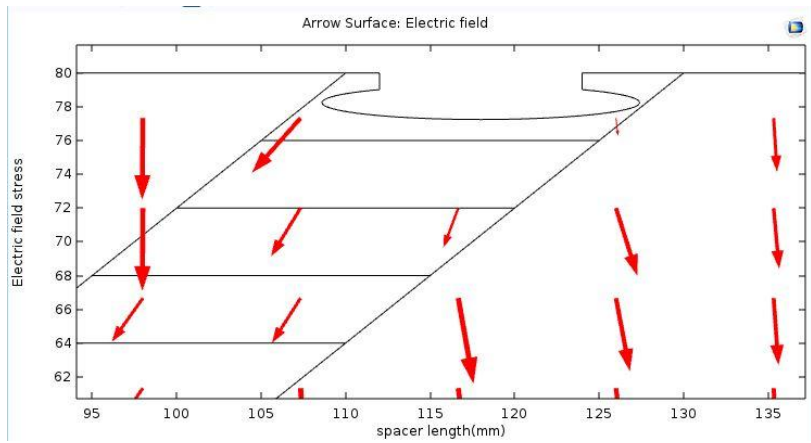

Fig 3: Quiver plot at Anode end / Type 1 / GL-FGM / With MI

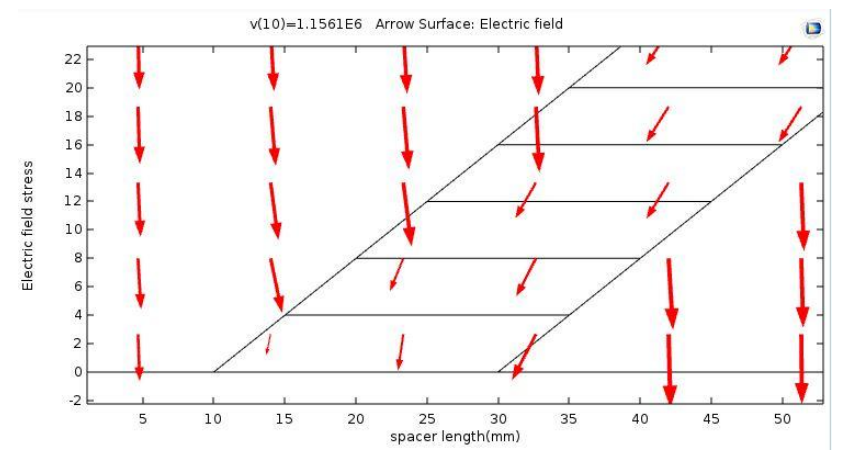

Fig 4: Quiver plot at Cathode end / Type 1 / GL-FGM

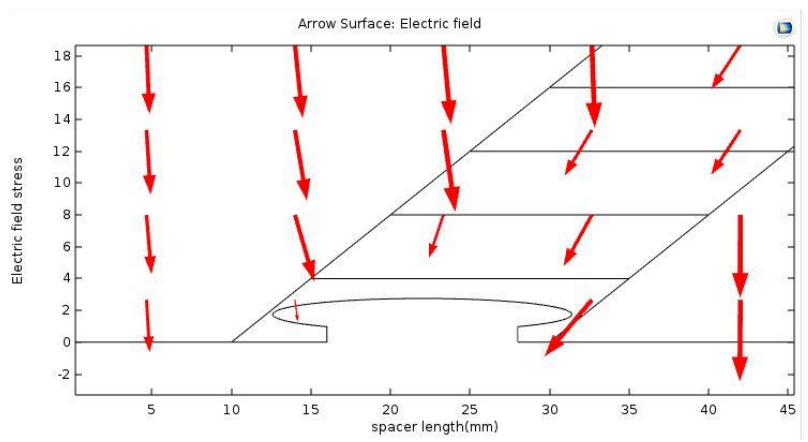

Fig 5: Quiver plot at Cathode end / Type 1 / GL-FGM / With MI

\section{RESULTS AND DISCUSSION}

In GIS SF6 and epoxy two important insulated medium employed, SF6 as a gas insulator, epoxy as a support insulator. This cone type spacer has a clearance of $80 \mathrm{~mm}$ between inner conductor and enclose. The applied voltage of a bus duct is $75 \mathrm{kV}$ with SF6 insulator permittivity as 1.005 and the outer electrode is connected to a ground. The technical FGM cone type spacer with three levels of permittivity is employed in this model. This entire model is developed by using COMSOL tool. For solve the electric field stress at near and for bus duct on a spacer during lightning impulse voltage of $1050 \mathrm{kV}$. The charge field stress along the spacer at worst case $\theta=(0,10,20,30, \ldots, 90)$ with and without inserter of $1156050 \mathrm{~V}(1.1561 \mathrm{E} 6 \mathrm{~V})$ as shown in fig $6-13$. From the fig 6 and 7 , at $\theta=90$ the maximum charge field stress with absence of MI is $1.68945 \mathrm{kV} / \mathrm{cm}$, when the same FGM cone type spacer with presence of MI gives $1.55114 \mathrm{kV} / \mathrm{cm}$, the reduced voltage from FGM with absence of MI to presence of MI is $0.13831 \mathrm{kV} / \mathrm{cm}$, it is nearly $91.81 \%$.

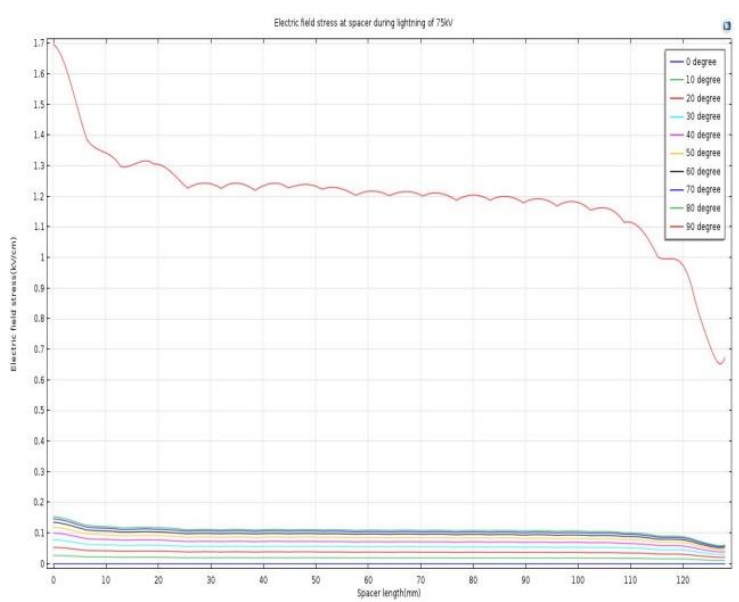

Fig 6: Field Stress for $75 \mathrm{kV}$ / without MI

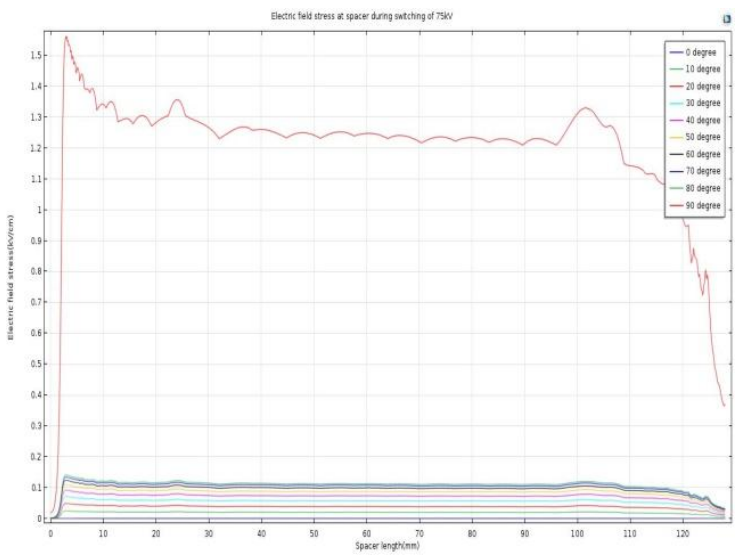

Fig 7: Field Stress for $75 \mathrm{kV}$ / with MI

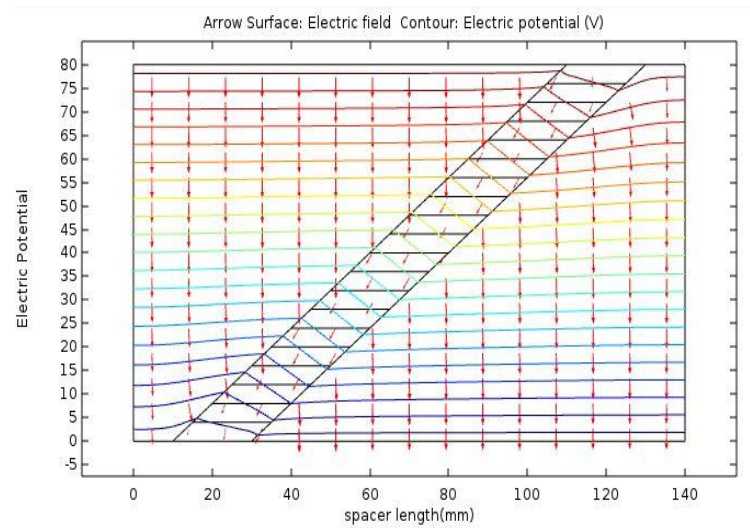

Fig 8: Field contour / 75kV / Without MI

Published By: 


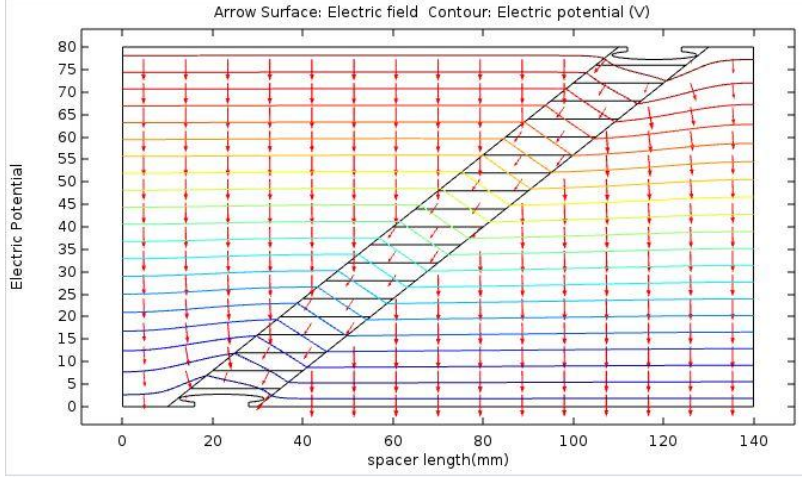

Fig 9: Field contour / 75kV / With MI

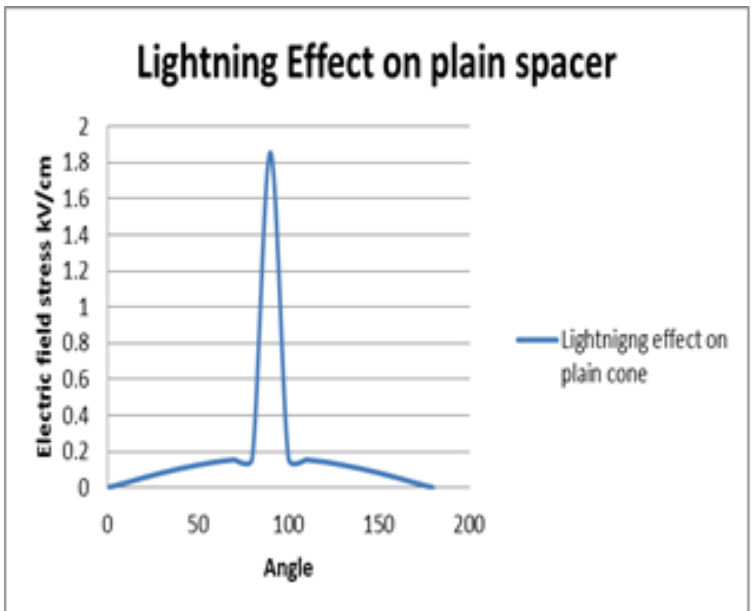

Fig 10: Field Stress for 75KV / plain spacer / Without MI

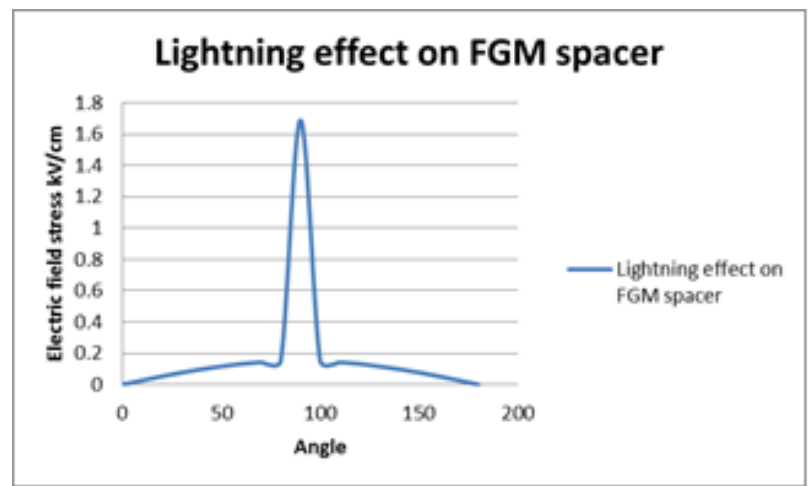

Fig:11 Field Stress for 75KV / FGM spacer / Without MI

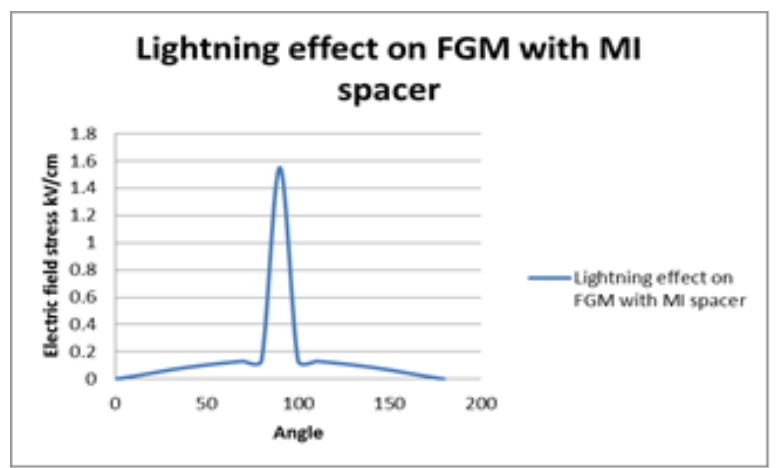

Fig:12 Field Stress for 75KV / FGM spacer / With MI

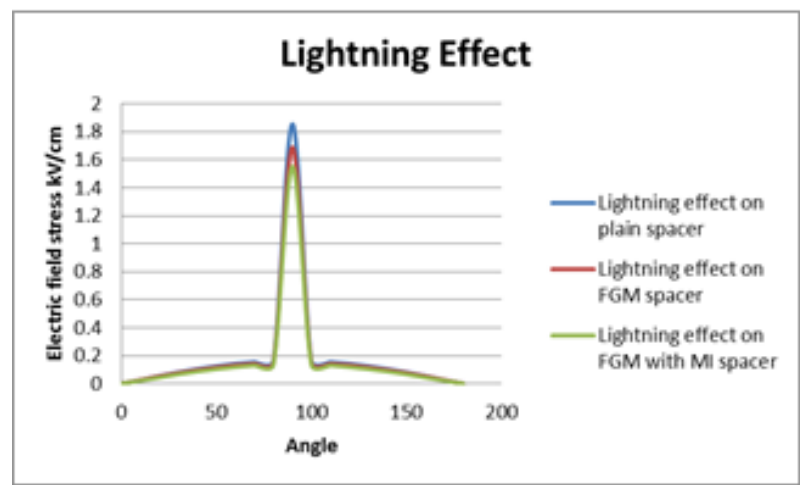

Fig:13 Comparsion of Field Stress

Charge field stress was reduced. When $175 \mathrm{kV}$ is applied at inner bus duct, so by employing the MI at FGM support insulator during lightning condition reduces by $91.81 \%$ of charge field stress, which can be minimized. That can be shown in Table 1. The flash over or break down of charge field strength, that improve the reliability of GIs. the three cases of permittivity levels had studied as shown in the Table 2, where permittivity levels of case 1 is less than case 2 and case 2 is less than case 3.here by increasing the permittivity levels, the charge field stress at inner and outer electrodes is going to decrease, because of increasing permittivity leads to increasing dielectric strength. This required more charge field stress to break that dielectric strength. Charge field stress without metal inserter is greater than charge field stress with metal inserter, that can be observed in same table and also decreasing charge field stress with increasing permittivity levels. the change in field stress at outer enclose from with and without metal inserter is approximately $98.85 \%$ for three cases and change in field stress at inner electrode from with and without metal inserter is approximately $44.64 \%$ for three cases from Table: 2

Table 1: Field stresses in $\mathrm{kV} / \mathrm{cm}$ along Spacer with metal inserts

\begin{tabular}{cccc}
\hline \hline & \multicolumn{3}{c}{ Applied Voltage 75 kV } \\
\hline \multirow{2}{*}{ Angle } & PLAIN & FGM & FGM with metal inserter \\
\cline { 2 - 4 } & $\begin{array}{c}\text { Electric field stress due to } \\
\text { Lightning kV/cm }\end{array}$ & $\begin{array}{c}\text { Electric field stress due to } \\
\text { Lightning kV/cm }\end{array}$ & $\begin{array}{c}\text { Electric field stress due to } \\
\text { Lightning kV/cm }\end{array}$ \\
\hline 0 & 0 & 0 & 0 \\
10 & 0.02621 & 0.02646 & 0.0219156 \\
20 & 0.055339 & 0.0529 & 0.0438312 \\
30 & 0.0815534 & 0.07669 & 0.0681818 \\
\hline \hline
\end{tabular}




\begin{tabular}{cccc}
\hline \hline 40 & 0.10485 & 0.09785 & 0.0876623 \\
50 & 0.12524 & 0.11635 & 0.104708 \\
60 & 0.142718 & 0.13222 & 0.119318 \\
70 & 0.154369 & 0.142797 & 0.131494 \\
80 & 0.163107 & 0.150729 & 0.136364 \\
90 & 1.85534 & 1.68945 & 1.55114 \\
100 & 0.163107 & 0.150729 & 0.136364 \\
110 & 0.154369 & 0.142797 & 0.131494 \\
120 & 0.142718 & 0.13222 & 0.119318 \\
130 & 0.12524 & 0.11635 & 0.104708 \\
140 & 0.10485 & 0.09785 & 0.0876623 \\
150 & 0.0815534 & 0.07669 & 0.0681818 \\
160 & 0.055339 & 0.0529 & 0.0438312 \\
170 & 0.02621 & 0.02646 & 0.0219156 \\
180 & 0 & 0 & 0 \\
\hline \hline
\end{tabular}

Table 2: Field stresses in $\mathrm{kV} / \mathrm{cm}$ without and with metal inserts during Lightning

\begin{tabular}{ccccc}
\hline \hline & \multicolumn{2}{c}{ Absence of MI } & \multicolumn{2}{c}{ Presence of MI } \\
\cline { 2 - 5 } & $\begin{array}{c}\text { Electric field } \\
\text { stress outer } \\
\text { encloser }\end{array}$ & $\begin{array}{c}\text { Electric field stress } \\
\text { inner electrode }\end{array}$ & $\begin{array}{c}\text { Electric field stress } \\
\text { outer encloser }\end{array}$ & $\begin{array}{c}\text { Electric field stress } \\
\text { inner electrode }\end{array}$ \\
Case & 1.68942 & 0.67947 & 0.019424 & 0.36934 \\
Case 1 & 1.67206 & 0.6725 & 0.01744 & 0.36924 \\
Case 2 & 1.67132 & 0.667762 & 0.017184 & 0.363339 \\
Case 3 & & & & \\
\hline \hline
\end{tabular}

\section{CONCLUSION}

Insulator support is the most important component to study in the GIS. Most of the insulation break down will occur at insulator support, due to non-uniform charge field stress along the surface to reduce the charge field stress, FGM technique is used, by this method, the charge field stress along surface will be uniform so that minimize the insulation break because uniform charge field density at Triple Point Junction (TPJ), this charge field density at TPJ will cause, the failure of insulator supporter. So to minimize the charge filed density at TPJ with use of metal inserts (MI). This entire technique is studied, under high lightning voltage of $1050 \mathrm{kV}$. During the lightning condition, there are impulse voltage disturbance at steady state, which cause insulation failure due to charge field stress. This can be minimized by the FGM with metal inserter technique

> The charge field stress was drastically reduced by moulding cone type fgm support insulator with metal inserter

$>$ By increasing the permittivity levels , dielectric strength of the support insulator will increases and charge field stress will decrease.

\section{REFERENCES}

1. Wang Haoran, Peng Zongren, Guo Zihao, Wang Qingyu, Li He, Liu Lilan " Electrical Field Influence of Metallic Particles and Inner Voids on UHV AC GIS Spacer" 2016 IEEE International Conference on Dielectrics(ICD), DOI:10.1109/ICD.2016.7547618,

2. Fuping Zeng, Ju Tang, Xiaoxing Zhang, Siyuan Zhou and Cheng Pan "Typical Internal Defects of Gas-Insulated Switchgear and Partial Discharge Characteristics" Submitted: December 4th 2017 Reviewed: May 24th 2018Published: October 17th 2018 DOI: 10.5772/intechopen.79090

3. Jagadeesh Adari , Venkata Siva Krishna Rao Gadi , Venkata Nagesh Kumar Gundavarapu " Mitigation of field stress with metal inserts for cone type spacer in a gas insulated busduct under delamination" Engineering Science and Technology, an International Journal 21 (2018) 850-861

4. Shigemitsu Okabe, Sadayuki Yuasa and Shuhei Kaneko " Evaluation of Breakdown Characteristics of Gas Insulated Switchgears for Non-standard Lightning Impulse Waveforms Breakdown Characteristics for Non-standard Lightning Impulse Waveforms Associated with Disconnector Switching Surges " IEEE Transaction on Dielectrics and Electrical insulation(Volume:14,issue:2,April 2007

5. A.K. Chakrabarti, R.G. van Heeswijk, K.D. Srivastava, "Free particle-initiated $60 \mathrm{~Hz}$ breakdown at a spacer surface in a gas-insulated bus", IEEE Trans. Electr.Insul. 24 (4) (1989) 549-560.

6. Evgeni Volpov, "Dielectric strength coordination and generalized spacer design rules for HVAC/DC SF6 Gas insulated systems", IEEE Trans. Dielectr. Electr. Insul.11 (6) (2004).

7. M. Gopi Chand Naik, J. Amarnath and S. 
Kamakshiah, "A New Optimised Design Of Single Phase Gas Insulated Cone Type Insulator," International Journal of Engineering Science and Technology, Vol. 4, pp.929-935, March 2012

8. Syarif Hidayat, Fransiskus Damanik, Umar Khayam " Electric Field Optimization on 150 kV GIS Spacer using Functionally Gradient Material" $2^{\text {nd }}$ international conference of industrial , mechanical 1, Electrical, and chemical Engineering ,DOI: 10.1109/ICIMECE 20167910457 IEEE

9. Sayed A, Ward, M, A. Abd Allah, Amr A. Youssef " Effect of Functionally Graded Material of Spacer with Contaminating Particle on Breakdown Voltage inside Gas Insulated Bus Duct" International Journal of Scientific \& Engineering Research, Volume 5, Issue 1, January-2014, ISSN 2229-55 